\title{
DO ONLINE STUDENTS DREAM OF ELECTRIC TEACHERS?
}

\author{
Jason A. Scorza \\ Fairleigh Dickinson University
}

\begin{abstract}
This paper represents a rough and ready attempt to describe an approach to online teaching that favors empathy over efficiency in the hope of achieving both.
\end{abstract}

\section{KEYWORDS}

Empathy, Teaching Presence, Desensitization, Online Learning, Pedagogy, Student Satisfaction

\section{INTRODUCTION}

Like many young people, I read quite a lot of science fiction while growing up and, as a result, the day dreams of my misspent suburban youth were filled with images of starships, space battles, alien life forms, and improbably attired inter-galactic warrior princesses. Space amazons aside, the science fiction literature of the second half of the twentieth century boasted many authors who explored fundamental questions about human nature, prejudice, cruelty, and compassion through depictions of the relationships between "normal" human beings and an eclectic variety of mutants, aliens, robots, androids, sentient computers, and intelligent apes. Science fiction writers like Isaac Asimov, Arthur C. Clarke, Stanislaw Lem, and Philip K. Dick were particularly intrigued by the idea of artificial persons, machines designed not just to imitate or approximate the appearance of human beings but actually to reproduce their capacity for self-awareness and an inner life. What moral status would such artificial persons have? Would ordinary human beings recognize them as equals worthy of consideration, compassion, and respect? How would they view ordinary human beings? How would they view one another?

It seems to me that these questions have gained new significance in the context of asynchronous learning, where student and instructor interaction is primarily text-based and computer-mediated. These communication systems make the development of relationships between students and instructors, and among students themselves, more difficult because they generally do not allow for the kinds of visual and oral cues permitted — but by no means guaranteed — by face to face learning. This is not to say that the consideration and compassion instructors feel for students necessarily will be diminished or that student expectation of an automatic (or mechanical) response from instructors will inevitably increase. However, few would deny that there is a strong probability that the distancing effect of computer-mediated asynchronous learning will cause many instructors and students to view one another more like extensions of the machines through which they are communicating than as real persons with emotions, aspirations, problems, time constraints and (in the case of most faculty) the very real need for sleep. As overworked online instructors turn to labor-saving shortcuts, such as computer software that can actually grade papers, and are compelled by the financial exigencies of higher education to increase their class sizes to unmanageable proportions, the problem of distancing is becoming increasingly serious [1].

Borrowing my title from Philip K. Dick's 1968 short novel Do Androids Dream of Electric Sheep?, I consider the extent to which online instructors seem "real" to their online students and what instructors 
can do to be (or become) more real, stepping out from behind the mediating technologies that threaten to obscure and disfigure them [2]. I have a hunch that theways in which students perceive the reality of their instructors is predicated upon how well they perceive their instructors perceiving them. In other words, if we can manage to show empathy, respect, compassion and consideration to our online students, not only through our course materials, course policies, and pedagogical methods, but also with respect to how we present ourselves [3], they will feel that they have taken a class taught by a real person and not an automaton, and consequently, the teaching and learning experience will be enhanced for everyone.

\section{THE EMPATHY ENGINE}

In his novel, Dick imagines a post-apocalyptic future in which the remnants of the human race view ownership of living animals, including both domestic dogs and cats and farm animals like horses and sheep, as a kind of status symbol. Caring for these animals also helps these emotionally isolated humans feel a sense of connectedness and, perhaps, even love for another being-feelings which the desensitizing nature of their existence, surrounded by a desolate and radioactive landscape and living in nearly abandoned apartment towers, threatens to undermine. Those who can't afford real animals purchase electronic simulacra manufactured by robotics corporations. These artificial animals are almost as good as the genuine article, although if they are not tended to they will break down (or "die") and everyone will know that one cannot afford a real sheep.

In this bleak dystopia a new religion called "Mercerism" has emerged in which individuals use a machine to "commune" with a persecuted and tormented martyr figure named Wilbur Mercer. Through this device, a kind of electronic "empathy engine," one can actually experience Mercer's suffering from his own point of view-literally, through his own eyes. Human beings in Dick's world also use a device called the "Penfield mood organ" to "dial" their mood for the day, programming their cerebral cortex much as a machine or computer is programmed. One can choose anything from "awareness of the manifold possibilities open to me in the future" to "the desire to watch TV no matter what's on it" [2]. Even such unlikely moods as "pleased acknowledgement of husband's superior wisdom in all matters" are available [2]. This machine also helps people cope with their circumstances-to survive emotionally, but certainly not flourish.

The line of separation between man and machine in Dick's imagined universe also is blurred. In addition to the robotic animals, corporations in Dick's world manufacture artificial human beings that are virtually indistinguishable from authentic humans but may, in spite of their condition of servitude on Mars and other off-world colonies, actually be superior [4]. Fearing the competition that these technological creations represent, and their complete lack of empathy, human beings seek to destroy the androids before they are themselves destroyed. Indeed, Rick Deckard, Dick's protagonist (played by Harrison Ford in the film version, Blade Runner), is an experienced bounty hunter trained to terminate (or "kill") renegade androids who escape their enslavement and attempt to pass for human.

Ironically, the very technologies that help human beings maintain an empathic link to one another, or to living animals, have the unintended side effect of making at least some people feel empathy for at least some androids. Deckard wonders, "Can you feel empathy for an artificial construct? For a machine” [2]? He concludes that he can, which is a serious problem for his career as a bounty hunter. Of course, Deckard does not feel empathy for all androids all of the time, or even for androids as such. However, some characters in the novel do seem to feel genuine generalized compassion for the androids. John Isidore, the so-called "chickenhead” mutant, certainly does. "'You're androids,' Isidore said. But he didn’t care; it made no difference to him” [2]. 
My main concern regarding online teaching, lifted from Dick's book, is not with the general and rather banal fear of the dangers of new technologies which, as in the Egyptian myth of Thoth and Thamos (and in many works of science fiction), forever threaten to destroy or dominate their creators. I certainly do not presume new technology as such to be dangerous. Rather, my concern is, more specifically, with the desensitization that both precipitates the development and use of certain technologies and which arises from this development and use.

When we talk about desensitization, it is the effect on people of graphic violence in television, film, and other entertainment that is most likely to come to mind. It is often argued that we can become so accustomed to cruelty and brutality that the perceived value of human life is diminished. However, it seems to me that computer mediated learning also is related to desensitization in two important ways. First, the general insensitivity of the corporate multiversity to the learning styles and needs of students has precipitated the development of online learning programs meant to "cash in" on new education markets and to "deliver instruction" with new economies of scale. Instructors who perceive unique opportunities to facilitate learning through asynchronous learning systems, and who begin with the best possible intentions, can soon end up "burning out" given the level of efficiency that the corporate model of online teaching requires.

Then there is the issue of alienation for faculty members. According to Marx, human beings pour their creative energy into making things (e.g., artifacts, institutions, belief systems, online courses) only to find those creations taken away from them and used to dominate them by a ruling class (namely, the bourgeoisie). Regrettably, this is the experience many online instructors have had with asynchronous learning. After toiling to create online courses they then confront those same courses as an alien force which threatens to dominate and oppress them (both in terms of the additional time required to teach and, in many cases, in terms of the loss to their institution of intellectual property rights). We are hoisted on our own petard, as it were. Indeed, the online course can begin to look to instructors a lot like the androids who return as a threat to humanity in Dick's novel.

Instructor burn-out and alienation leads to a second form of desensitization. As instructors begin to take necessary shortcuts they find themselves efficiently performing routine operations upon students whose learning styles and needs are actually quite heterogeneous. These students, in turn, become desensitized as their instructors begin to appear almost robotic in their provocations and responses (or even to disappear altogether, becoming, as a matter of fact and not just as a figure of speech, ghosts in the machine). Viewed in this light, even some veteran online instructors have concluded that temporal and geographic "distance" necessarily translates into "emotional distance," notwithstanding that emotional distance also is apparent in the large lecture hall and the moderately sized classroom of the overloaded instructor. Indeed, scholars such as Glenn Russell have concluded that technological mediation tends to diminish the experience of empathy compared with immediate (or face to face) interaction [5]. Unfortunately, there is no such thing as an electronic empathy engine that we can plug ourselves into in order to identify with the feelings and experiences of other people. This leaves online instructors with the challenge of developing pedagogical strategies for avoiding one kind of desensitization (found in the alienating online environment) in spite of the pressures created by the other (found in the demands of the corporate multiversity).

\section{EMPATHY ONLINE}

Daniel Pink, in A Whole New Mind (2005), argues that capacities for empathy, creativity and storytelling will emerge as central to the new economy, even in fields that have been driven up to now primarily by pure analytical thinking and raw technical ability [6]. However, the capacity for empathy, Pink argues, 
depends upon the ability to read non-verbal indicators. As Pink writes, "Since empathy depends on emotion and since emotion is conveyed nonverbally, to enter into another's heart, you must begin the journey by looking into his face" [6]. This view recalls Emerson, who observes, "Strange that any body who ever met another person's eyes, should doubt that all men have one soul. We look into the eyes to know if this other form is another self; and the eyes will not lie, but they give a faithful confession what inhabitant is there" [7].

Leaders in the study of empathy's role in distance learning would tend to agree, and many advocate increased use of technologies like video-conferencing that will allow learners and instructors to interact with one another in real time [8]. Unfortunately, such technologies remain prohibitively expensive and, in any case, reliance upon them would undermine the "anywhere anytime" promise of asynchronous learning. We must hope, therefore, that the answer to the empathy question can be found through pedagogy rather than technology.

My own online teaching experience at Fairleigh Dickinson University thus far has been with courses that emphasize discussion and dialogue, which is essential for instructors who want to maintain a substantial online presence. Indeed, the ability to engage in serious and civil dialogues on controversial topics is identified as a priority learning objective in courses such as The Life of the Mind (PHIL 1000), an introductory philosophy course, The Global Challenge (CORE A), an interdisciplinary global issues course, and Ethics \& Public Affairs (PHIL 4438), an upper level philosophy offering. Enrollment in these classes is limited to twenty or fewer students, which permits (but does not guarantee) improved response times and personal attention by instructors. Also, all were taught in "blended" formats, meeting between six and twelve times per semester. This usually has the impact of reducing, although not eliminating, the distancing effect, as do the following more specific methods that I have used in particular classes.

\section{A. Presentation of Course Materials}

Whenever possible I like to adopt a conversational tone in online course materials, even making use of humor, where it is appropriate (and sometimes even where it is not), to make the non-interactive aspects of the course more welcoming. It is also important to address the student directly (as you) rather than in the abstract and to say please and thank you. Additionally, providing interactive elements within the course materials is helpful in creating a less alienating learning environment. The famous Allegory of the Cave, from Plato's "Republic," is presented in The Life of the Mind in an interactive graphical format, allowing students to identify and understand different symbolic elements of Plato's argument. (Visit the interactive Plato's Cave here: http://alpha.fdu.edu/edtech/plato.htm.) This course also provides original interactive lecture notes which prompt students for responses, offer opportunities for reflection, supply humorous responses, and use a variety of multimedia techniques to help illuminate the meaning of complex philosophical arguments. In the notes for Week Nine, for instance, a sequence of crucial quotations on the philosophy of war is presented. Each quotation is accompanied by hyperlinks providing interpretation, as well as a provocative interactive question that provides feedback to a range of student responses. (To see an example of the lecture notes go to: http://alpha.fdu.edu/edtech/LOTM/10_2_il 1102 index.htm.) We also use audio, sometimes just to break up the monotony but often to draw attention to a crucial point. An audio clip from the movie "Duck Soup," in which the anti-authoritarian Marx Brothers ask a critical question about authority, is just one example. (See http://alpha.fdu.edu/ scorza/LOTM/Marx/yourowneyes.html.) And, what introduction to philosophy course would be complete without Monty Python's "Philosophers Song"? (See http://alpha.fdu.edu/ scorza/LOTM/Python/philosophysong5.html.) Use of these techniques has led to significant debates with colleagues who, fearing that students will take the course materials and the course less seriously, prefer a more formal textbook style. However, it is a mistake to de-personalize such a major aspect of the course. 


\section{B. Course Policies}

Although I do not permit anonymous posts in my courses, I do like to create two kinds of "safe space" for student discussions. First, I believe that it is important for online students to have their own discussion boards away from the prying eyes of their instructor. Admittedly, there always is the temptation to "peek," but with hundreds of other discussion board posts to read, time constraints usually trump idle curiosity. Additionally, I like to provide a public social space, in the form of a course "coffee shop," which provides students with an outlet for "off topic" chat. This also allows them to engage in before class and after class chat, an experience which they would otherwise be denied in an asynchronous online format. Sometimes the professor even drops by for a virtual "cup of joe.”

I also try to be reasonable about setting deadlines and granting extensions for written work. Some students may take advantage of this. However, the price to be paid for being overly fastidious about deadlines is plummeting morale. Many students choose online learning because of its flexibility. Expecting these students to satisfy deadlines in robotic fashion is a mistake (and encourages them to expect me to respond to them just as mechanically). I must confess that I learned this the hard way with my first online course, The Global Challenge, in which I initially required students to submit seven papers on a strict schedule (every other Sunday at midnight without fail). This policy resulted in a lot of poor student work and an unsatisfactory level of learning. That being said, I do demand that students keep up with the online discussions. The ability to engage in thoughtful and civil dialogues with one another about controversial philosophical and political questions becomes impossible if too many members of the class fall too far behind.

\section{Guidelines and Evaluation}

When I first started teaching online I created elaborate guides to writing papers and participating in discussions that, I am almost certain, very few of my students actually read. My thinking, as I recall, was that I needed to tell my students everything they needed to know about their assignments by answering every conceivable question in advance. In retrospect, I realize how counterproductive this was. While it is important to provide clear instructions for assignments, in bullet format whenever possible, it is not necessary to present overly elaborate guidelines which will, more likely than not, leave students confused or intimidated.

On the other hand, I do like to share my actual grading rubrics with students. Rubrics simultaneously create transparency and also give me reference points when providing feedback on assignments. And, when it comes to such feedback, the timeliness of one's response is an important consideration but not the only consideration. A quick response should not come at the expense of providing personalized comments for each student, addressed to them by name. It never hurts to end the feedback with a friendly "Please let me know if you have any questions!” followed by your e-mail address. This is like having a welcome mat with an “@” sign on it.

The best form of evaluation, however, is self-evaluation. In The Life of the Mind I have experimented with self-assessments which ask students to examine critically their own learning processes. At the start of each semester, I request that all students submit a brief essay describing what they take to be their greatest academic strength and their greatest academic weaknesses, along with an account of how they will make the most of their strength and minimize their weakness. Midway through the course, I ask for comments on how they are doing so far and, in particular, how they are managing their strengths and weaknesses. A similar exercise is conducted at the end of the semester. I find that since students generally are much harder on themselves than I am likely to be, I can more be supportive and understanding in my feedback, creating a positive mentoring dynamic rather than one that is merely critical. 


\section{Pedagogical Method}

Dialogue and collaborative problem-solving are central to my courses. Indeed, the study of philosophy is traditionally pursued through Socratic dialogue, in which participants consent to have their ideas and opinions exposed to examination and criticism by the group. Students engage in this collaborative process every week and cannot satisfy course learning objectives without doing so. Asynchronous discussionswhich take place over the course of several days, rather than in a single class session-also give students more time to compose their thoughts, potentially enhancing the quality of discussion; this is especially important in a philosophy-based offering, in which questions often require extended periods of reflection (as well as interaction) [9]. Compared with the traditional classroom, which forces shy students to be silent and encourages "shotgun" responses from the more vocal, the online discussion board encourages the contemplative life. Online discussions also provide more opportunities for students to respond directly to one another, rather than engaging in back-and-forth discussion only with the instructor; this is especially important for a course like The Life of the Mind in which students are encouraged to develop philosophic positions in dialogue with others, or a course like The Global Challenge, in which students are asked to collaboratively address complex global problems.

The discussion board also allows me to draw upon a network of faculty and practitioners from around the world-Fairleigh Dickinson University's "Global Virtual Faculty" — who partner with instructors, illuminating the practical significance of philosophical ideas. For example, a forensic investigator from Scotland Yard discusses philosophy of science; a United Nations peacekeeping official discusses democratic philosophy and philosophy of war; and a human rights activist from New Zealand leads a discussion of ethics. (See the Global Virtual Faculty program roster at: http://globaleducation.edu/gv /roster.html.) Working with these colleagues enables me to model the practice of Socratic dialogue online, engaging in lively discussions with members of the Global Virtual Faculty in the presence of the class. Students are, then, urged to engage in this practice themselves. As the semester unfolds, instructors often can step back and perform the role of facilitator, posting topics at the start of the week and occasionally steering the discussion back to central questions or drawing special attention to a point made by a student that might otherwise be overlooked.

Even with small class sizes, the volume of fruitful discussion can be overwhelming, sometimes exceeding 200 distinct posts in a given week. This does, occasionally, make me feel like an automatic discussion board reading machine, but it is essential since the pedagogical price to be paid for falling too far behind-and losing "teaching presence"-is incalculable. Although my role is ideally limited to facilitation (or "directing traffic"), students are clearly more engaged when they consistently feel the presence of the instructor than when they are left to their own devices in the barren landscape of the asynchronous discussion board.

\section{E. Presentation of Self}

To these four rather obvious dimensions of the online course, I would hazard the addition of a fifth. As with any complex social situation, how we present ourselves has a lot to do with how we are going to be perceived and also with how people are going to respond to us. I am convinced that there is nothing wrong with sharing personal anecdotes, using the first person on discussion boards, generating a sense of personal warmth, and using humor (including the self-deprecating variety), in addition to providing personal responses to student comments and questions. You can even admit when you are reading their discussion board posts in the kitchen while drinking hot chocolate or when you need to take a break to go feed the cat or tell your child a bedtime story. If our students come to understand that we are real people, and not efficient mechanical grading machines, and if we (reciprocally) show that we know that they are real people, and not automatic essay writers and test takers, then they will find the online learning 
environment less alienating and desensitizing and we may all sleep better (if not more).

\section{CONCLUSION}

In the final analysis, compassion and empathy (either in an online or in a traditional course) means never giving up on students. This can be difficult when you are being bombarded weekly with hundreds of discussion board posts for each class, and when you are carrying a four course teaching load each semester. It is understandable, and perhaps even excusable, that you sometimes wish that some of your students would just go away. Indeed, when a student has not posted on the discussion board for three weeks, it is tempting to hope that you never hear from him or her again (since papers and discussion board posts that go unwritten also never need to be read or evaluated). However, the potential of online teaching and learning can only be realized when students and instructors see each other as real and valuable, and treat each other accordingly.

\section{ACKNOWLEDGEMENTS}

I would like to thank the Sloan Consortium for honoring me with the 2004 Award for Excellence in OnLine Teaching. In justice, this award is shared with my friends and collaborators Walter Cummins, Christopher Devine, Leonard Grob, Jennifer Lehr, Linda-Elfers Mabli, and Lana Tiersky. I also am indebted to the students of Fairleigh Dickinson University who have participated (some more willingly than others) in these challenging experiments in learning and to our global virtual faculty Tomas Chuaqui, James Gallagher, Sunaina Lowe, and Anna Varkonyi for sharing with these students their unique perspectives in our online discussions. I would also like to express my gratitude to Jon Cottrell, Joy McDonald, Mahesh Nair, and Subhojit Paul for providing technical support and expertise for my online courses; to Paula Mayhew, Pamela Schneider, and Martin Green for their invaluable help with learning outcomes assessment; to Francis Ingledew for countless discussions of online pedagogy; and to Catherine Kelley for all of the above.

My work in this area would not have been possible without the personal encouragement of Michael Sperling and John Snyder and the institutional support of the Office of Educational Technology, the Office of Global Learning, the University Core program, the University College dean's office, and the School of English, Philosophy \& Humanities. Finally, as a relative newcomer to asynchronous learning, I also am extremely grateful to the pioneers in the field. Without their vision and dedication there would not have been a bandwagon for me to jump on.

\section{REFERENCES}

1. Gilbert, Alorie. Teachers leave grading up to the computer. CNET News.com: April 7, 2005. http://news.zdnet.com/2100-3513_22-5659366.html.

2. Dick, Philip K. Do Androids Dream of Electric Sheep? New York: Ballantine, 1968.

3. Holmberg, Börje. Theory of Distance Education Based on Empathy. In: Michael G. Moore and William Anderson (Eds.), Handbook of Distance Education. Mahwah, NJ: Erlbaum, 2003.

4. Davis, Erik. The Metaphysics of Philip K. Dick. Wired 11 (12): 7, December 2003.

5. Russell, Glen. The Distancing Question in Online Education. Innovate 1 (4): March 5, 2005. http://www.innovateonline.info/index.php?view=article\&id=13.

6. Pink, Daniel H. A Whole New Mind: Moving From the Information Age to the Conceptual Age. New York: Penguin, 2005.

7. Emerson, Ralph Waldo. The Heart. In: The Early Lectures of Ralph Waldo Emerson, Vol. II. Cambridge, MA: Harvard University Press, 1972. 
8. Russell, Glen. The Distancing Dilemma in Distance Education. International Journal of Instructional Technology and Distance Learning 1 (2): February 2003. http://wired-vig.wired.com/wired/archive/11.12/philip.html?pg=6\&topic=\&topic set=.

9. Garrison, D. Randy, Martha Cleveland-Innes and Tak Fung. Student Role Adjustment in Online Communities on Inquiry: Model and Instrument Validation. Journal of Asynchronous Learning Networks 8 (2): April 2004. http://www.sloan-c.org/publications/jaln/v8n2/v8n2_garrison.asp

\section{ABOUT THE AUTHOR}

Jason A. Scorza teaches philosophy and humanities courses at Fairleigh Dickinson University, where he is Director of the School of English, Philosophy \& Humanities and the School of Art \& Media Studies. $\mathrm{He}$ also is General Editor of Global Issues Gateway (http://www.gig.org), a global learning website developed by Fairleigh Dickinson University. Scorza received his B.A. in political science and history from Rutgers University in 1990 and his Ph.D. in politics from Princeton University in 1997. 